\title{
Deguelin inhibits human hepatocellular carcinoma by antiangiogenesis and apoptosis
}

\author{
JU-HEE LEE ${ }^{1 *}$, DON-HAENG LEE ${ }^{1 *}$, HYUN-SEUNG LEE ${ }^{2}$, JOON-SEOK CHOI ${ }^{2}$, \\ KYU-WON KIM ${ }^{2}$ and SOON-SUN HONG ${ }^{1}$ \\ ${ }^{1}$ College of Medicine, Inha University, 7-206, 3-ga, Sinheung-dong, Jung-gu, Incheon 400-712; \\ ${ }^{2}$ College of Pharmacy, Seoul National University, Seoul 151-742, Korea
}

Received February 14, 2008; Accepted March 26, 2008

\begin{abstract}
Deguelin is a rotenoid isolated from several plant species, which has been reported to have chemopreventive effects in skin, mammary, colon and lung cancers. The effects of deguelin on the proliferation and apoptosis of hepatic cancer cells were assessed by MTT assay and flow cytometric analysis. The growth of hepatic cancer cells (HepG2, Huh7 and SK-Hep1) was inhibited by deguelin in a dose-dependent manner. HepG2 cells of all the cell lines were the most sensitive to deguelin $\left(\mathrm{IC}_{50}=0.62 \mu \mathrm{M}\right)$. The proportion of sub-G1 apoptotic cells increased from 5.19 to $41.27 \%$ by deguelin $(0.01-10 \mu \mathrm{M})$ treatment for 3 days in the HepG2 cells. The effects of deguelin on anti-angiogenesis of the HepG2 cells were assessed by using Western blot and RT-PCR analysis. Treatment of HepG2 cells with deguelin for $16 \mathrm{~h}$ under hypoxia conditions reduced the expression of the hypoxia-inducible factor $1 \alpha$ protein and vascular endothelial growth factor mRNA in a dose-dependent manner. In order to investigate whether deguelin shows antiangiogenic activities, we performed in vitro and in vivo angiogenesis assays. In a tube formation assay, deguelin remarkably reduced the capillary network formation of human umbilical vein endothelial cells (HUVECs) on Matrigel beds. Furthermore, deguelin markedly decreased the migration of HUVECs compared to the control and reduced angiogenesis on the CAM of chick embryos. These results suggest that deguelin is potentially useful as a chemotherapeutic agent in hepatocellular carcinoma.
\end{abstract}

Correspondence to: Dr Soon-Sun Hong, College of Medicine, Inha University, 7-206, 3-ga, Sinheung-dong, Jung-gu, Incheon 400-712, Korea

E-mail: hongs@inha.ac.kr

${ }^{*}$ Contributed equally

Key words: deguelin, hepatocellular carcinoma, HepG2, apoptosis, angiogenesis

\section{Introduction}

Hepatocellular carcinoma (HCC) is the fifth most common cancer and the third leading cause of cancer-related death worldwide (1). HCC may be one of the most common fatal cancers, especially in east Asian countries $(2,3)$. HCC has characteristics of rapid growth rate, strong malignancy, easy invasion, metastasis and poor prognosis and the occurrence of hepatoma presented in an ascending trend. However, the curative effect of current therapies in liver cancer is not perfect (4). Therefore, the development of chemotherapeutic or chemopreventive agents for HCC is very important in reducing the mortality caused by this disease.

Deguelin is a rotenoid of the flavonoid family isolated from several plant species including Mundulea sericea (Leguminosae) (5) and a naturally occurring insecticide. It has previously been reported as an inhibitor of activated Akt with chemopreventive properties $(5,6)$. Deguelin has been shown to be a potential chemopreventive agent against breast, skin and colon cancers $(6,7)$. Deguelin has also been reported to effectively prevent tobacco carcinogen-induced lung carcinogenesis by blocking Akt activation $(5,6)$ and has shown antiproliferative and apoptotic activities in certain non-small cell lung cancer (NSCLC) cell lines in vitro $(8,9)$. Furthermore, deguelin has recently shown potential to be an angioprevention and antiangiogenic therapeutic agent in human umbilical vein endothelial cells (HUVECs) and cancer targeting hypoxia-inducible factor $1 \alpha(\mathrm{HIF}-1 \alpha)$ $(6,10,11)$.

Although, deguelin has shown potential chemopreventive activities against several types of cancers, the effects of deguelin in hepatic cancer cells have not been defined. In the present study, we examined the effects of deguelin on the proliferation in HCC cells and then investigated the apoptosis and angiogenesis for the mechanism. As a result, we found that deguelin inhibits the progression of HCC by the antiangiogenesis and apoptosis pathway.

\section{Materials and methods}

Cells and materials. The human HCC cell lines HepG2, Huh7 and SK-Hep1 were obtained from the Korean Cell Line Bank (KCLB, Seoul, Korea). These cell lines were cultured in 
Dulbecco's modified Eagle's medium (DMEM), supplemented with $10 \%$ fetal bovine serum (FBS) and $1 \%$ penicillinstreptomycin. FBS, cell culture media, antibiotics and all other reagents used in cell culture studies were purchased from Seoulin Science Co. (Seoul, Korea). Cultures were maintained at $37^{\circ} \mathrm{C}$ in a $\mathrm{CO}_{2}$ incubator with a controlled humidified atmosphere composed of $95 \%$ air and $5 \% \mathrm{CO}_{2}$.

For hypoxic stimulation, dishes were placed in an incubator with $1 \% \mathrm{O}_{2}, 5 \% \mathrm{CO}_{2}$ and $94 \% \mathrm{~N}_{2}$ in a humidified atmosphere for the times indicated. HUVECs were grown in a gelatincoated $75-\mathrm{cm}^{2}$ flask in an M199 medium containing $3 \mathrm{ng} / \mathrm{ml}$ basic fibroblast growth factor (bFGF), $5 \mathrm{U} / \mathrm{ml}$ heparin and $20 \% \mathrm{FBS}$ at $37^{\circ} \mathrm{C}$ in a humidified atmosphere of $5 \% \mathrm{CO}_{2} / 95 \%$ air. The cells used in this study were from passages 5 to 6 .

Deguelin was manufactured from the natural product rotenone (Sigma-Aldrich, Milwaukee, WI, USA) via four steps and was dissolved in dimethyl sulfoxide (DMSO) at a stock concentration of $20 \mathrm{mM}$ and was stored at $-20^{\circ} \mathrm{C}$.

Measurement of cell proliferation. To measure the effects of deguelin on cell proliferation, HepG2, Huh7 and SK-Hep1 cells were plated at a concentration of $1 \times 10^{3}$ to $4 \times 10^{3}$ cells/well in 96-well plates. After incubation for one day, cells were treated with either DMSO as a control or various concentrations of deguelin. The final concentration of DMSO in the medium was $\leq 0.5 \%(\mathrm{v} / \mathrm{v})$; at this concentration, DMSO had no effect on cell growth. After the cells were incubated for 3 days, cell proliferation was measured by the 3-(4,5dimethylthiazol-2-yl)-2,5-diphenyltetrazolium bromide (MTT) assay as described previously (12). Three replicate wells were used for each analysis. The drug concentration required to inhibit cell growth by $50 \%\left(\mathrm{IC}_{50}\right)$ was determined by interpolation from dose-response curves.

Cell cycle analysis. HepG2 cells were plated in 100-mm culture dishes. The next day, cells were treated with various concentrations of deguelin or DMSO (0.5\%) for 3 days. Floating and adherent cells were harvested and fixed with $70 \%$ ethanol overnight at $4^{\circ} \mathrm{C}$. After washing, the cells were subsequently stained with $50 \mu \mathrm{g} / \mathrm{ml}$ propidium iodide (Sigma Chemical Co., St. Louis, MO, USA) and $100 \mu \mathrm{g} / \mathrm{ml}$ RNase A (Qiagen) for $1 \mathrm{~h}$ and subjected to flow cytometric analysis in order to determine the percentage of cells at specific phases of the cell cycle as described (13). Flow cytometric analysis was performed using a FACScalibur flow cytometer (Becton Dickinson, San Jose, CA, USA) equipped with a 488-nm argon laser. Events $(\sim 20,000)$ were evaluated for each sample and the cell cycle distribution was calculated by using CellQuest (Becton Dickinson) software. The results were presented as the number of cells versus the amount of DNA as indicated by the intensity of the fluorescence signal. Three independent experiments were performed.

RT-PCR analysis. To assess the effects of deguelin on mRNA expression by reverse-transcriptase polymerase chain reaction (RT-PCR) analyses, HepG2 cells were treated with various concentrations of deguelin in a complete medium for $16 \mathrm{~h}$ under hypoxic conditions.
A

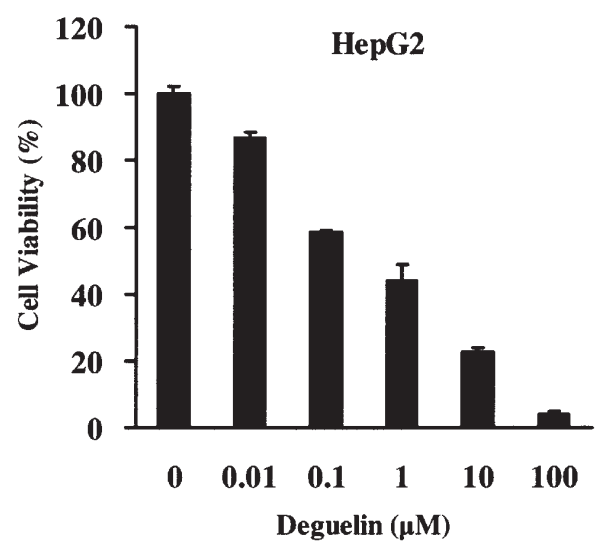

$\mathbf{B}$

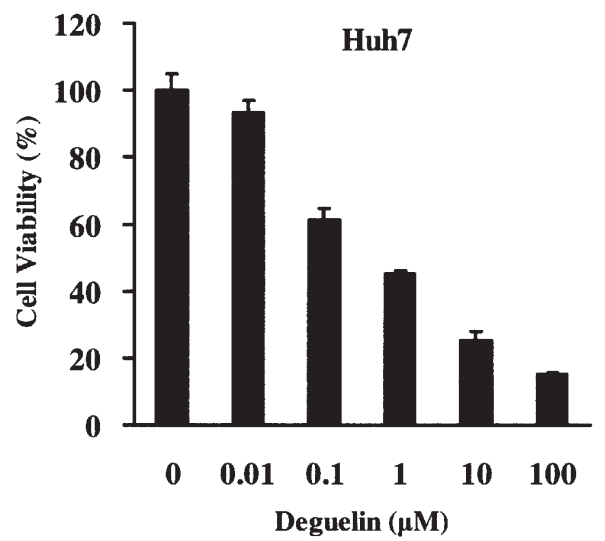

C

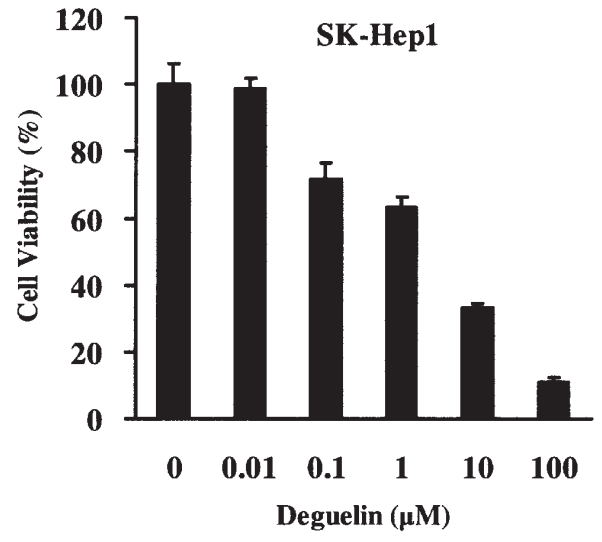

Figure 1. Effects of deguelin on the proliferation of human hepatocellular carcinoma (HCC) cells. HepG2 (A), Huh7 (B) and SK-Hep1 (C) cells were seeded in 96 -well culture plates ( $1 \times 10^{3}$ to $4 \times 10^{3}$ cells/well). After incubation for one day, the cells were treated with various concentrations of deguelin or with $0.5 \%$ dimethyl sulfoxide (DMSO) as a control. After incubation for 3 more days, they were subjected to MTT assay. Results are expressed as percent cell proliferation relative to the proliferation of DMSO-treated cells (control). Each value is the mean $( \pm \mathrm{SD})$ from three identical wells.

Total RNA from the cells was isolated using Trizol reagent (Life Technologies) according to the manufacturer's instructions. First-stranded cDNA was synthesized by Moloney murine leukemia virus reverse transcriptase with $5 \mu \mathrm{g}$ of each DNA-free total RNA sample and oligo(dT) ${ }^{15}$ (Life Technologies, Grand Island, NY) according to the manufacturer's instructions. Equal amounts of cDNA were subsequently amplified by PCR in a $50 \mu 1$ reaction volume containing 1X PCR buffer, $200 \mu \mathrm{M}$ dNTPs, $10 \mu \mathrm{M}$ specific primer for each gene and 1.25 units Taq DNA polymerase 

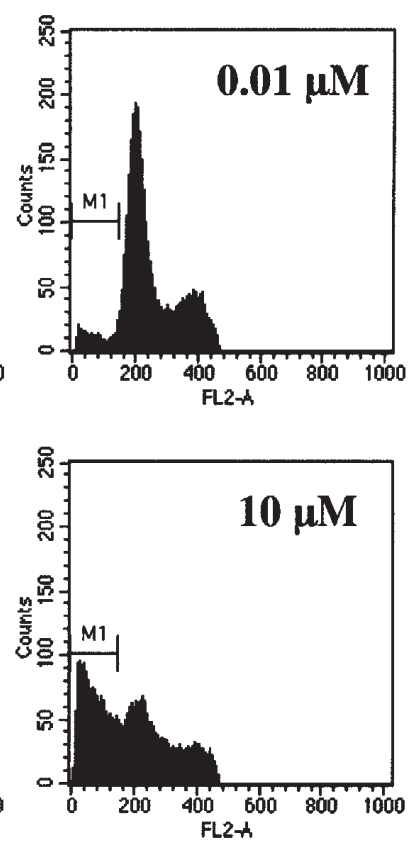

$\mathbf{A}$
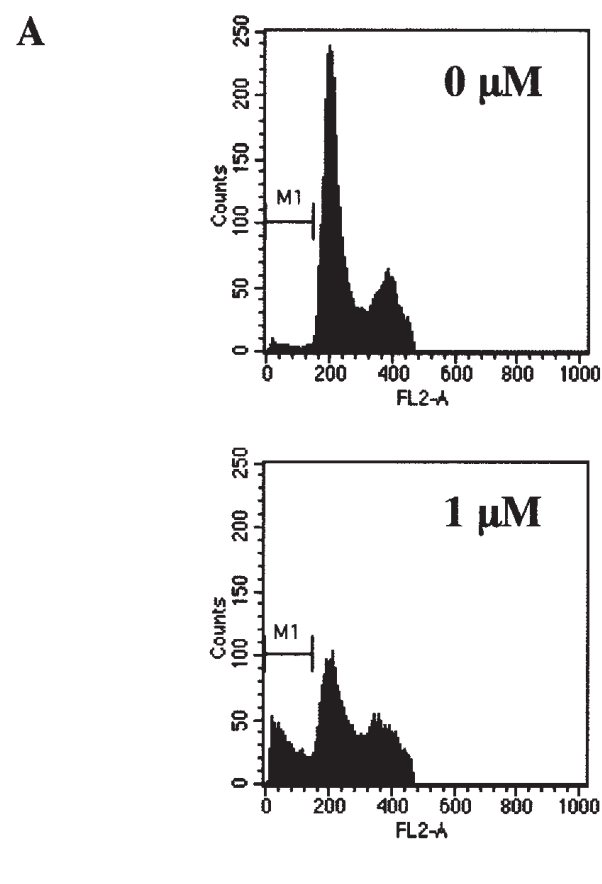

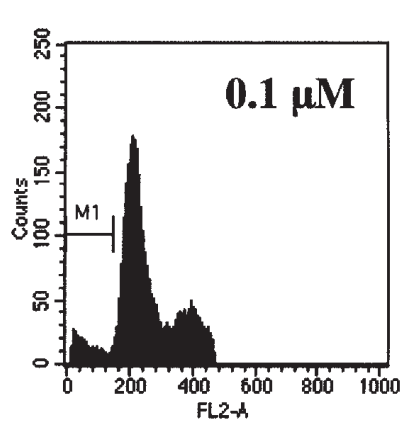

.

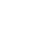

B

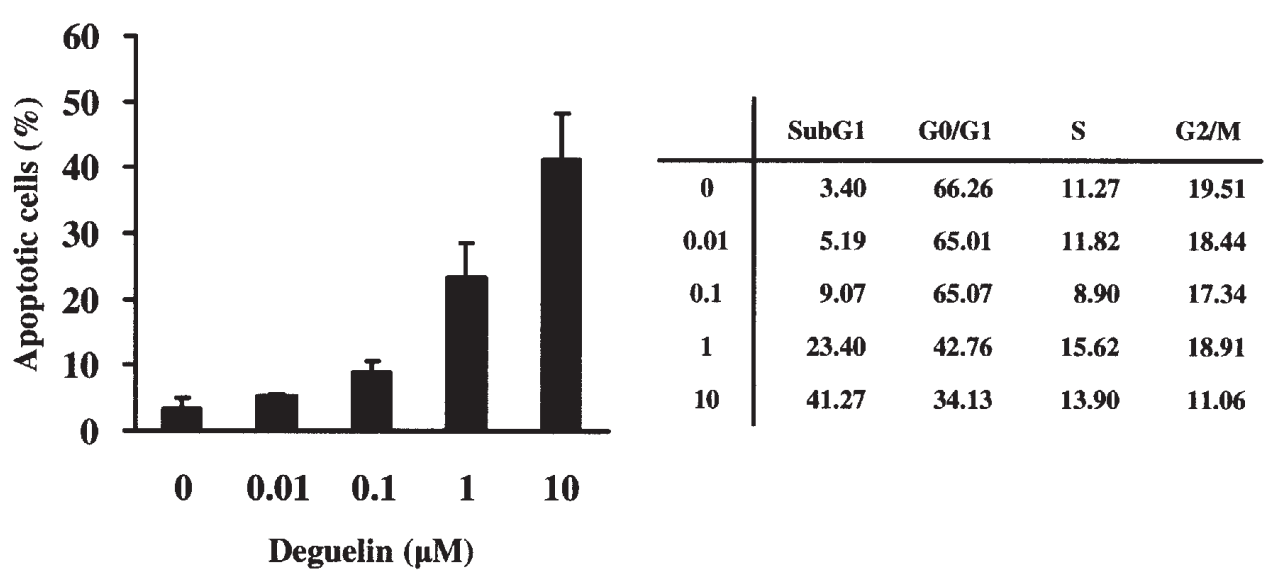

Figure 2. Effect of deguelin on cell cycle distribution of HepG2 cells. (A) HepG2 cells were incubated with deguelin for 3 days, stained with propidium iodide (PI) and analyzed on a FACScalibur flow cytometer. M1, sub-G1. (B) The sub-G1 materials after 3 days of incubation were quantified and plotted against the concentrations of deguelin.

(Perkin-Elmer). GAPDH was used as an internal control cDNA amplification. Amplification products were separated on agarose gels and visualized by ethidium bromide staining under UV transillumination. The primer sequences were as follows: (sense) 5'-GGCCTCCGAAACCATGAACTTT CTG-3' and (antisense) 5'-CCTCCTGCCCGGCTCACCGC-3' for VEGF; (sense) 5'-ACCACAGTCCATGCCATCAC-3' and (antisense) 5'-TCCACCACCCTGTTGCTGTA-3' for GAPDH.

Western blot assay. To assess the effects of deguelin on protein expression by Western blot, HepG2 cells were treated with various concentrations of deguelin in a complete medium for $16 \mathrm{~h}$ under hypoxic conditions. Cells were lysed in a lysis buffer containing $40 \mathrm{mM}$ Tris- $\mathrm{HCl}$ (pH 7.4), 10 mM EDTA, $0.1 \% \mathrm{NP}-40$ and $120 \mathrm{mM} \mathrm{NaCl}$. Protein concentration was determined with the use of a BCA protein assay kit following the manufacturer's instructions (Sigma Chemical Co). Whole cell lysates were resolved in SDS-polyacrylamide gels followed by electrophoretically transferring them onto nitrocellulose membrane (Hybond ${ }^{\mathrm{TM}} \mathrm{ECL}$ ) and probed with anti-HIF- $1 \alpha$ (BD Biosciences, San Diego) and anti- $\alpha$-tubulin (InnoGenex) antibodies. The bands were visualized with the ECL plus system (ECL).

Tube formation assay. Matrigel $(250 \mu \mathrm{l})(10 \mathrm{mg} / \mathrm{ml})$ (BD Biosciences, New Jersey) was polymerized for $30 \mathrm{~min}$ at $37^{\circ} \mathrm{C}$. HUVECs $\left(5 \times 10^{4}\right.$ cells/48-well) were seeded on Matrigel and treated with deguelin $(1 \mu \mathrm{M})$ for $8 \mathrm{~h}$. The morphological changes of the cells and tubes formed were observed under a phase-contrast microscope and photographed at x 200 magnification.

Wounding migration assay. HUVECs, plated on 60-mm culture dishes at $90 \%$ confluence, were wounded with a razor blade $2 \mathrm{~mm}$ in width and marked at the injury line. After wounding, the cultures were washed with a serum-free medium and further incubated in DMEM with $1 \%$ serum, $1 \mathrm{mM}$ thymidine 
A

$\begin{array}{lccccc}\text { Deguelin }(\mu \mathrm{M}) & - & - & 0.01 & 0.1 & 1 \\ \text { Hypoxia } 16 \mathrm{~h} & - & + & + & + & +\end{array}$

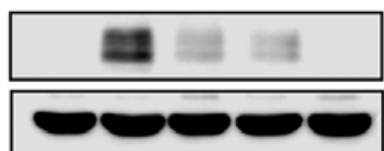

$\leftarrow \operatorname{HIF-1\alpha }$

$\leftarrow$ tubulin

B

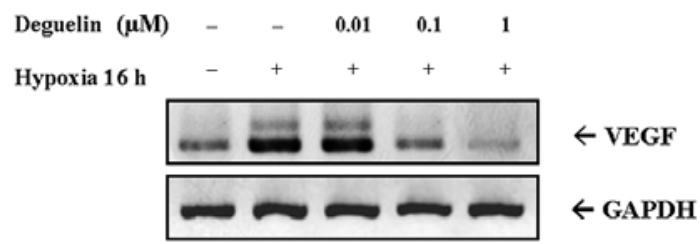

Figure 3. Deguelin inhibits HIF-1 $\alpha$ and VEGF expression. (A) Western blot analysis on HIF-1 $\alpha$ in HepG2 cells untreated $(-)$ or treated $(+)$ with deguelin. (B) RT-PCR analysis on VEGF mRNA expression in HepG2 cells untreated $(-)$ or treated $(+)$ with deguelin. and/or deguelin (0.1-1 $\mu \mathrm{M})$. HUVECs were allowed to migrate for $11 \mathrm{~h}$ and were rinsed with a serum-free medium, followed by fixing with absolute methanol and staining with Giemsa. Migration was quantitated with counting the number of cells that moved beyond the reference line.

Chick chorioallantoic membrane (CAM) assay. Fertilized chick eggs were incubated under conditions of a constant humidified egg breeder at $37^{\circ} \mathrm{C}$. On the third day of incubation, $\sim 3 \mathrm{ml}$ of egg albumin were aspirated by an 18-gauge hypodermic needle in order to detach the developing CAM from the shell. At 4.5 days, sample-loaded thermanox coverslips (Nunc, Naperville, IL) were air-dried and applied to the CAM surface for the testing of angiogenesis inhibition by deguelin (4 $\mu \mathrm{g} / \mathrm{egg}$ ). Two days later, $1-2 \mathrm{ml}$ of $10 \%$ fat emulsion (Intralipose) was injected into the chorioallantois and observed under a microscope.

\section{Results}

Inhibition of cell proliferation. To evaluate the inhibitory effect of deguelin on the growth of HepG2, Huh7 and SK-Hep1
$\mathbf{A}$

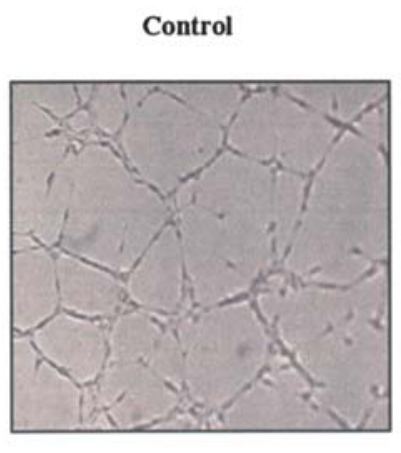

B

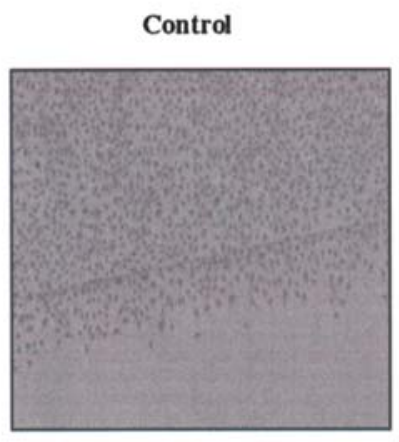

Control

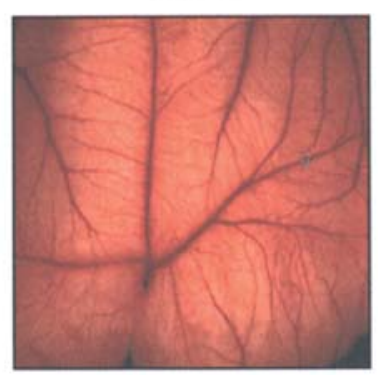

\section{Deguelin (1 uM)}

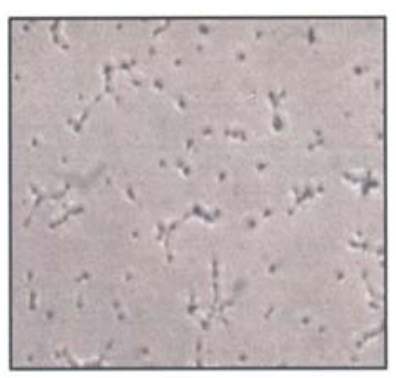

Deguelin (1 uM)
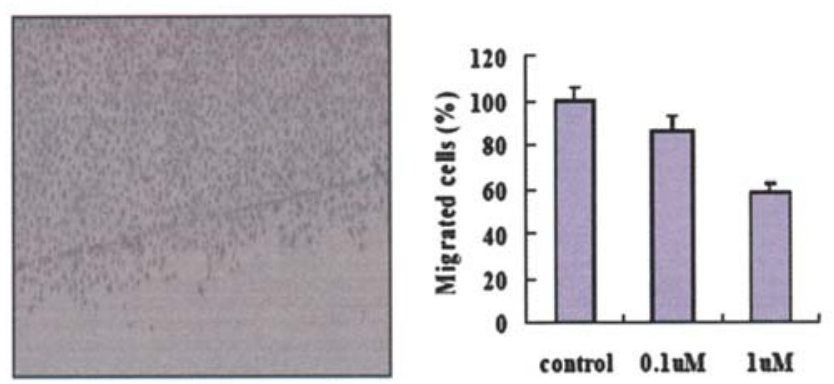

RA

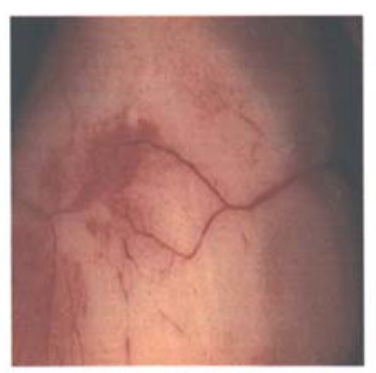

Deguelin

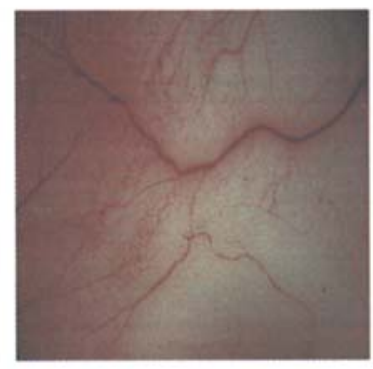

Figure 4. The effect of deguelin on the tube formation, migration in vitro and embryo vasculogenesis. (A) Representative images depicting the formation of capillary-like tube structures by HUVECs following $8 \mathrm{~h}$ of treatment with DMSO (control) or the indicated concentration of deguelin (1 $\mu \mathrm{M}$ ). (B) Migration of deguelin-treated HUVECs compared with the control. (C) CAM surfaces were treated with vehicle (control), retinoic acid (RA) as a positive control, or deguelin (4 $\mu \mathrm{g} / \mathrm{egg})$, respectively. 
cells, the culture was exposed to various concentrations of deguelin for up to 3 days. Deguelin was evaluated at five concentrations from 0.01 to $100 \mu \mathrm{M}$. It was found that cell growth was inhibited in a dose-dependent manner (Fig. 1). The $\mathrm{IC}_{50}$ of deguelin for 3 days of treatment were $0.62,0.74$ and $4.99 \mu \mathrm{M}$ in HepG2, Huh7 and SK-Hep1, respectively. HepG2 cells of all the cell lines were the most sensitive to deguelin.

Deguelin induces apoptosis. Alterations of the cell cycle of HepG2 cells exposed to deguelin were investigated by flow cytometry. Cells incubated with different concentrations of deguelin for 3 days were analyzed for the distribution of sub-G1, G0/G1, S and G2/M phases of the cell cycle.

Apoptosis can result in the progressive generation of particles corresponding to hypodiploid DNA content, which reflects DNA fragmentation (14-16). Therefore, the amount of apoptotic cells was calculated based on the appearance of cells in 'sub-G1' (17). Fig. 2A shows untreated HepG2 cells (control) at a normal cell cycle stage, consisting of a major diploid peak (G0/G1), a small hyperdiploid region (S) and a minor tetraploid peak (G2/M). However, deguelin pretreatment $(0.01-10 \mu \mathrm{M})$ led to the increase of the percentage of sub-G1, reflecting that cells had undergone apoptosisassociated DNA degradation, where sub-G1 apoptotic cells increased from 5.19 to $41.27 \%$ (Fig. 2B).

Effect of deguelin on the HIF-1a and VEGF expression in $H C C$. Hypoxia is the major stimulus for angiogenesis and HIF- $1 \alpha$ is its key mediator (18). Since HIF-1 plays a crucial role in tumor progression by regulating the expression of key apoptotic and angiogenic factors, including VEGF (11), we examined whether deguelin influences the expression pattern of HIF- $1 \alpha$ and VEGF. Treatment of HepG2 cells with $0.01-1 \mu \mathrm{M}$ deguelin for $16 \mathrm{~h}$ under hypoxic conditions reduced the expression of HIF-1 $\alpha$ protein (Fig. 3A) and VEGF mRNA (Fig. 3B) in a dose-dependent manner.

Deguelin inhibits angiogenesis in vitro and in vivo. To investigate whether deguelin shows antiangiogenic activities, we performed in vitro and in vivo angiogenesis assays. HUVECs were plated onto Matrigel where they normally aligned and formed a tube-like structure (19). However, in the tube formation assay, deguelin remarkably reduced the capillary network formation of HUVECs on Matrigel beds. The tube structures were not elongated and the cells were made a rump and did not develop into a tube network (Fig. 4A). Furthermore, deguelin markedly decreased the migration of HUVECs compared to the control (Fig. 4B). Moreover, we confirmed the antiangiogenic effect of deguelin in vivo with a chick embryo CAM assay. The chick embryos treated with retinoic acid (RA) as a positive control for the angiogenesis inhibitor showed a reduced vessel formation. Deguelin remarkably reduced angiogenesis on the CAM of chick embryos (Fig. 4C). These results strongly suggest that deguelin potently represses angiogenesis by inhibiting migration and tube formation of endothelial cells.

\section{Discussion}

Many cancer chemopreventive agents, including naturally occurring and synthetic compounds, have been studied for their in vivo and in vitro antitumor efficacy (7). Most drugs currently available for the treatment of cancer are mechanistically based on the inhibition of cell proliferation and induction of apoptosis (20). Deguelin is a rotenoid of the flavonoid family isolated from several plant species and has shown potential as a chemopreventive agent against breast, skin, colon and lung cancers $(6,7)$. In our studies, we examined effects of deguelin on the proliferation of various HCC cells. The growth of HepG2, Huh7 and SK-Hep1 cells were inhibited in a dose-dependent manner (Fig. 1). HepG2 cells of all the cell lines were the most sensitive to deguelin $\left(\mathrm{IC}_{50}=0.62 \mu \mathrm{M}\right)$. Considering that the $\mathrm{IC}_{50}$ value of deguelin for colon cancer was $0.43 \mu \mathrm{M}$ (7), it seemed to have a strong efficacy in HCC.

We further investigated the mechanism by which deguelin inhibits cell proliferation. Chemotherapeutic agents causing apoptosis have been increasingly appreciated as ideal compounds for the management of cancer (21). Previous studies have reported that deguelin can trigger apoptosis in tumor cells in vitro (22). Deguelin promoted cell cycle arrest in the colon and lung cancer cells, which was followed by apoptosis induction (22). In colon cancer cells, deguelin arrested cells in the G0/G1 phase of the cell cycle at incubation for $24 \mathrm{~h}$ in the HT-29 cells and was associated with a sub-G1 peak at $72 \mathrm{~h}$ (7). Premalignant and malignant human bronchial epithelial (HBE) cells treated with deguelin accumulated in the $\mathrm{G} 2 / \mathrm{M}$ phase of the cell cycle and underwent apoptosis in a dose- and time-dependent manner (6). Therefore, in order to investigate the possible pathway that was involved with the anticancer effect of deguelin, the apoptosis of HepG2 cells was analyzed in vitro. Although cell cycle arrest was not affected by deguelin treatment in our studies, we have demonstrated that the increase of a sub-G1 peak in a dose-dependent manner, which indicates that deguelin may be potentially mediating its actions by inducing apoptosis in these cells. These data support the potent apoptotic effects of deguelin on HCC.

Another possible pathway that was involved with the anticancer effect of deguelin in vitro and in vivo was examined in our study. Angiogenesis, the formation of new blood vessels from pre-existing endothelium, is integral to tumor growth and metastases (23). The angiogenic process is tightly controlled by a wide variety of positive or negative regulators, such as growth factors, cytokines, lipid metabolites and cryptic fragments of hemostatic proteins (19). In addition, hypoxia stimulates angiogenesis in order to support tumor growth by inducing the expression of angiogenic factors, such as insulin-like growth factor II and VEGF and HIF- $1 \alpha$ is its key mediator $(18,24)$. Recently, the drug development targeting hypoxia has evoked an extensive interest in cancer therapy (25). HIF-1 $\alpha$ is a new target for the antiangiogenic therapy of HCC. Deguelin has been reported to be antiangiogenic targeting HIF- $1 \alpha$ in lung cancer $(11,26)$. Therefore, we investigated antiangiogenic activities of deguelin in HCC. As a result, deguelin inhibited hypoxiainduced angiogenesis via down-regulating the expression of the HIF-1 $\alpha$ protein and VEGF mRNA in HepG2 cells. Furthermore, our study reveals that deguelin inhibits angiogenic features of HUVECs in vitro as revealed by a capillary-like tube formation and migration assays. In addition, 
deguelin treatment significantly inhibited neovascularization in vivo in the CAM assay.

Most anticancer drugs such as tubulysin A (tub A), sulforaphane, phenethyl isothiocyanate (PEITC) and 6-(1oxobutyl)-5,8-dimethoxy-1,4-naphthoquinone (OXO) induce apoptosis as well as inhibit angiogenesis to achieve therapeutic efficacy (20,27-29). Especially, curcumin, resveratrol, YC-1 and rapamycin have been reported to target HIF-1 $\alpha$ in HCC (30-34). In our study, we demonstrated that deguelin induced apoptosis as well as inhibited angiogenesis in HCC and HUVECs. Therefore, we suggest that deguelin is potentially useful as a chemotherapeutic agent in HCC.

Taken together, our data indicated that deguelin had anticancer activity, which was correlated with the inhibition on angiogenesis and the induction of apoptosis in HCC. Deguelin may be a potential agent in inhibiting the progression of HCC by antiangiogenesis and the apoptosis pathway.

\section{Acknowledgements}

This study was supported by the Inha University Research Grant (INHA-33608-1).

\section{References}

1. Parkin DM, Bray F, Ferlay J and Pisani P: Estimating the would cancer burden: Globocan 2000. Int J Cancer 94: 153-156, 2001.

2. Yoo SM, Oh SH, Lee SJ, et al: Inhibition of proliferation and induction of apoptosis by tetrandrine in HepG2 cells. J Ethnopharmacol 81: 225-229, 2002.

3. Bae JM, Won YJ, Jung KW and Park JG: Annual report of the Korean central cancer registry program 2000. Cancer Res Treat 34: 77-83, 2002.

4. Song GB, Luo Q, Qin J, Wang L, Shi YS and Sun CX: Effects of oxymatrine on proliferation and apoptosis in human hepatoma cells. Colloids Surf B 48: 1-5, 2006.

5. Lee HY, Oh SH, Woo JK, et al: Chemopreventive effects of deguelin, a novel Akt inhibitor, on tobacco-induced lung tumorigenesis. J Natl Cancer Inst 97: 1695-1699, 2005.

6. Chun KH, Kosmeder JW II, Sun S, et al: Effects of deguelin on the phosphatidyl-inositol 3-kinase/Akt pathway and apoptosis in premalignant human bronchial epithelial cells. J Natl Cancer Inst 95: 291-302, 2003.

7. Murillo G, Salti GI, Kosmeder JW II, Pezzuto JM and Mehta RG: Deguelin inhibits the growth of colon cancer cells through the induction of apoptosis and cell cycle arrest. Eur J Cancer 38: 2446-2454, 2002.

8. Lee HY, Suh YA, Kosmeder JW II, Pezzuto JM and Kurie JM: Deguelin-induced inhibition of cyclooxygenase-2 expression in human bronchial epithelial cells. Clin Cancer Res 10: 1074-1079, 2004.

9. Lee HY: Molecular mechanisms of deguelin-induced apoptosis in transformed human bronchial epithelial cells. Biochem Pharmacol 68: 1119-1124, 2004.

10. Dell'eva R, Ambrosini C, Minghelli S, Noonan DM, Albini A and Ferrari N: The Akt inhibitor deguelin, is an angiopreventive agent also acting on the NF-кB pathway. Carcinogenesis 28: 404-413, 2007.

11. Oh SH, Woo JK, Jin Q, et al: Identification of novel antiangiogenic anticancer activities of deguelin targeting hypoxia-inducible factor-1 alpha. Int J Cancer 122: 5-14, 2008.

12. Lee HY, Chun KH, Liu B, et al: The effects of insulin-like growth factor binding protein-3 on lung cancer. Cancer Res 62: 3530-3537, 2002 .

13. Sun SY, Yue P, Shroot B, Hong WK and Lotan R: Induction of apoptosis in human non-small cell lung carcinoma cells by a novel synthetic retinoid CD437. J Cell Physiol 173: 279-284, 1997.
14. Ho PJ, Chou CK, Kuo YH, Tu LC and Yeh SF: Taiwanin A induced cell cycle arrest and p53-dependent apoptosis in human hepatocellular carcinoma HepG2 cells. Life Sciences 80: 493-503, 2007.

15. Sheng HU, Chen SM, Li XK, Qin R and Mei ZN: Antitumor effects of Chi-Shen extract from Salvia miltiorrhiza and Paeoniae radix on human hepatocellular carcinoma cells. Acta Pharmacol Sin 28: 1215-1223, 2007.

16. Lee SJ, Ko WG, Kim JH, et al: Induction of apoptosis by a novel intestinal metabolite of ginseng saponin via cytochrome $\mathrm{c}-/$ mediated activation of caspase -3 protease. Biochem Pharmacol 60: 677-685, 2000.

17. Li J, Cheung HY, Zhang Z, Chan GKL and Fong WF: Androprapholide induces cell cycle arrest at G2/M phase and cell death in HepG2 cells via alteration of reactive oxygen species. Eur J Pharmacol 568: 31-44, 2007.

18. Tang N, Wang L, Esko J, et al: Loss of HIF-1 alpha in endothelial cells disrupts a hypoxia-driven VEGF autocrine loop necessary for tumorigenesis. Cancer Cell 6: 485-495, 2004.

19. Jun HO, Kim YH, Kwon YW, et al: Wondonin, a novel compound, inhibits hypoxia-induced angiogenesis through hypoxia-inducible factor 1 alpha. FEBS Lett 581: 4977-4982, 2007.

20. Kaur G, Hollingshead M, Holbeck S, et al: Biological evaluation of tubulysin A: a potential anticancer and antiangiogenic natural product. Biochem J 396: 235-242, 2006.

21. Debatin KM: Activation of apoptosis pathways by anticancer drugs. Adv Exp Med Biol 457: 237-244, 1999.

22. Hail N Jr and Rotan R: Apoptosis induction by the natural product cancer chemopreventive agent deguelin is mediated through the inhibition of mitochondrial bioenergetics. Apoptosis 9: 437-447, 2004.

23. Li L, Ahmed B, Mehta K and Kurzrock R: Liposomal curcumin with and without oxaliplatin: effects on cell growth, apoptosis, and angiogenesis in colorectal cancer. Mol Cancer Ther 6: 1276-1282, 2007.

24. Wu XZ, Xie GR and Chen D: Hypoxia and hepatocellular carcinoma: The therapeutic target for hepatocellular carcinoma. J Gastroenterol Hepatol 22: 1178-1182, 2007.

25. Nagasawa H, Uto Y, Kirk KL and Hori H: Design of hypoxiatargeting drugs as new cancer chemotherapeutics. Biol Pharm Bull 29: 2335-2342, 2006.

26. Oh SH, Woo JK, Yazici YD, et al: Structural basis for depletion of heat shock protein 90 client proteins by deguelin. J Natl Cancer Inst 99: 949-961, 2007.

27. Asakage M, Tsuno NH, Kitayama J, et al: Sulforaphane induces inhibition of human umbilical vein endothelial cells proliferation by apoptosis. Angiogenesis 9: 83-91, 2006.

28. Xiao D and Singh SV: Phenethyl isothiocyanate inhibits angiogenesis in vitro and ex vivo. Cancer Res 67: 2239-2246, 2007.

29. Lee HJ, Lee HJ, Song GY, et al: 6-(1-Oxobutyl)-5,8dimethoxy-1,4-naphthoquinone inhibits Lewis lung cancer by antiangio-genesis and apoptosis. Int J Cancer 120: 2481-2490, 2007.

30. Bae MK, Kim SH, Jeong JW, et al: Curcumin inhibits hypoxia-induced angiogenesis via down-regulation of HIF-1. Oncol Rep 15: 1557-1562, 2006.

31. Choi H, Chun YS, Kim SW, Kim MS and Park JW: Curcumin inhibits hypoxia-inducible factor-1 by degrading aryl hydrocarbon receptor nuclear translocator: a mechanism of tumor growth inhibition. Mol Pharmacol 70: 1664-1671, 2006.

32. Zhang Q, Tang X, Lu QY, Zhang ZF, Brown J and Le AD: Resveratrol inhibits hypoxia-induced accumulation of hypoxiainducible factor- 1 alpha and VEGF expression in human tongue squamous cell carcinoma and hepatoma cells. Mol Cancer Ther 4: 1465-1474, 2005

33. Lau CK, Yang ZF, Lam CT, Tam KH, Poon RT and Fan ST: Suppression of hypoxia inducible factor- 1 alpha (HIF-1 alpha) by YC-1 is dependent on murine double minute 2 (Mdm2). Biochem Biophys Res Commun 348: 1443-1448, 2006.

34. Wang Z, Fan J, Zhou J, et al: Inhibition of growth and metastasis of hepatocellular carcinoma by rapamycin: experiment with mice. Zhonghua Yi Xue Za Zhi 86: 1666-1670, 2006. 